\title{
Japanese B Encephalitis: An Overview of the Disease and Use of Chimerivax-JE as a Preventative Vaccine
}

\author{
Ruth Chin · Joseph Torresi
}

To view enhanced content go to www.infectiousdiseases-open.com

Received: August 8, 2013 / Published online: November 19, 2013

(C) The Author(s) 2013. This article is published with open access at Springerlink.com

\section{ABSTRACT}

The Japanese encephalitis virus (JEV) is endemic in many countries in southern Asia and the western Pacific Rim, with new spread to previously unrecognized countries. It is an important cause of childhood neurological disease associated with permanent neurological sequelae and death. Fortunately,

R. Chin $\cdot$ J. Torresi

Department of Medicine, Austin Hospital,

University of Melbourne, Heidelberg 3084, Australia

R. Chin

Victorian Infectious Diseases Service, Royal

Melbourne Hospital, Parkville 3010, Australia

J. Torresi (凶)

Department of Infectious Diseases, Austin Hospital, The University of Melbourne, 145 Studley Road, Heidelberg, VIC 3084, Australia e-mail: josepht@unimelb.edu.au

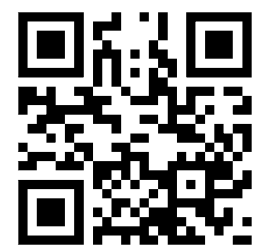

Enhanced content for this article is

available on the journal web site:

www.infectiousdiseases-open.com
$\mathrm{JE}$ is a vaccine-preventable disease. The ChimeriVax $^{\mathrm{TM}}$-JE (Sanofi Pasteur, Lyon, France) is a live-attenuated chimeric vaccine derived from the live-attenuated yellow fever virus, YF17D, which expresses the envelope proteins of the attenuated JEV vaccine strain, SA14-14-2. It is a safe, well-tolerated vaccine that is highly immunogenic in adults and children. The average geometric mean neutralizing antibody titer (GMT) in adults is 1,392 and over $90 \%$ of adults remain seroprotected 5 years after vaccination. In children and toddlers, more than $80 \%$ remain seroprotected 2 years after primary vaccination and demonstrate a robust and durable anamnestic response ( $>500$-fold rise in GMT) with $99.1 \%$ seroprotection rates 1 year after a booster vaccine dose. The ChimeriVax ${ }^{\mathrm{TM}}$-JE is effective in children living in endemic regions where the vaccine could possibly be integrated into existing childhood vaccination programs. ChimeriVax ${ }^{\mathrm{TM}}$-JE is also indicated for travelers at risk of JE infection.

Keywords: Booster vaccine; Immunogenicity; Infectious diseases; Japanese encephalitis; Liveattenuated vaccine; Vaccines 


\section{INTRODUCTION}

Japanese encephalitis virus (JEV) causes a serious and potentially life-threatening infection of the central nervous system of which children are the most affected. Although the majority of infections are asymptomatic, the case fatality is estimated at $20-30 \%$ in those who develop clinical disease and up to $50 \%$ of survivors experience life-long neuropsychiatric sequelae $[1,2]$. There is no specific antiviral treatment for JE infection but with the availability of safe effective vaccines that can be integrated into existing childhood vaccination programs in endemic countries, there is an opportunity to reduce the adverse health and economic burden of JEV disease.

Currently, there are three commercial vaccines licensed for use in several regions of the world [3-5]. This review will focus on the live-attenuated JE-chimeric vaccine [ChimeriVax ${ }^{\mathrm{TM}}$-JE; also known as IMOJEV and JE-CV (Sanofi Pasteur, Lyon, France)]. It is a safe and effective prophylactic vaccine against JE for adults and children over 12 months of age, and represents a significant advance from the mouse brain-derived inactivated JE vaccine that had been available since 1955. There is emerging evidence that ChimeriVax ${ }^{\mathrm{TM}}$-JE is capable of eliciting long-lasting immunity, even after a single dose of vaccine, making this vaccine an attractive option for use in JE endemic regions of the world.

\section{METHOD}

The analysis in this article is based on previously conducted studies, and does not involve any new studies of human or animal subjects performed by any of the authors. This review was conducted through a MEDLINE search, limited to the English language, from 1980 to June 2013 using the following search terms and filters: Japanese encephalitis, natural history, virology and vaccine. Manual-search of reference list of relevant studies, clinical trials and reviews was also conducted.

\section{Virology of JEV}

JEV belongs to the family of Flaviviridae, genus Flavivirus, and shares antigenic cross-reactivity with other members of the Flavivirus genus including dengue virus, Murray Valley encephalitis virus, Kunjin virus, West Nile Virus and St Louis encephalitis virus. It is an enveloped, spherical virus that contains an 11-kb single stranded, positive-sense RNA genome. The viral genome encodes a single polyprotein that is cleaved into three structural proteins (capsid, membrane and envelope) and seven non-structural proteins (NS1, NS2A, NS2B, NS3, NS4A, NS4B and NS5). The envelope, E, protein is involved in host receptor binding and entry, neurovirulence and tissue tropism, and is the major antigenic determinant of the host immune response $[6,7]$.

There are four major genotypes of JEV based on the envelope gene, and each genotype has been shown to have a relatively specific regional geographic distribution. Genotypes I and III predominate in the more temperate regions of Korea, Japan, China, Taiwan, Philippines, northern Thailand and Cambodia. These viruses are often associated with epidemics of JE. In contrast, genotypes II and IV are associated with endemic infection in southern Thailand, Malaysia and Indonesia [8]. Genotype $V$ was identified in association with an epidemic of encephalitis in Malaysia in 1952 [8] and has been isolated in the mosquito vector, Culex tritaeniorhynchus, in China [9]. 


\section{Transmission Cycle of JEV and Geographic Distribution}

JEV is transmitted in a zoonotic cycle between mosquitoes, water birds and pigs. The principal mosquito vector is the Culex mosquito, in particular, C tritaeniorhynchus, an evening- and night-time biting mosquito [10]. Mosquitoes are zoophilic, feeding on wading birds (herons and egrets) and pigs, which are the primary hosts in the infection cycle. JEV infection causes high-titer viremia in pigs, which are increasingly recognized as the most important ecological reservoir for JE in the amplification and spread of JEV [7]. Humans are incidental end-hosts in the lifecycle of JEV and not necessary for the maintenance of the viral transmission due to low-titer viremia in humans that is insufficient to infect the biting mosquito vectors.

JEV is widely distributed throughout Asia and the Pacific rim, with peak endemicity centered on equatorial Asia and seasonal epidemics occurring in the more temperate regions of southeast Asia, India, Japan, Korea, Taiwan and mainland China (Fig. 1) [11-14]. In the tropical and subtropical regions of Asia, transmission of JEV occurs year-round, peaking during the rainy season, while in the northern temperate regions, JE follows an epidemic pattern and is more prevalent during and after the monsoon rains in summer and autumn. JE infection in humans has been tracked according to rainfall patterns, mosquito numbers and seroconversion in sentinel animals [15]. More recently, JEV has been identified in the Torres Strait Islands and in the Cape York Peninsula of Far North Queensland in Australia [16-18] and also in Tibet, formerly believed to be a non-endemic region [19].

\section{Incidence of JE in Endemic Populations and Travelers}

It has been difficult to accurately determine the incidence of JE infection because the majority of infections are subclinical [20]. The extent to which measures to control the mosquito vector, improvements in agricultural and commercial animal husbandry practices and JE vaccination programs have impacted on the overall incidence of JE infection has not been accurately quantified. In 2011, the World Health Organization (WHO) surveillance data estimated that the incidence of JE infection was 1.8 per 100,000 persons, approximately 67,900 new cases annually. However, with $75 \%$ of cases occurring in children, the annual incidence in those aged $0-14$ years was 5.4 per 100,000, 3 times higher than the overall incidence [21].

The expansion of global travel, tourism and economic opportunities in Asia has seen a large number of travelers from non-endemic regions visiting and living in JEV endemic regions, and this population represents an emerging group at risk of acquiring JE infection [22-24]. The overall risk of acquisition of JE in travelers is difficult to ascertain, as the risk relates directly to activities that increase the likelihood of mosquito bites, including season and duration of travel, travel to rural areas, outdoor activities and accommodation lacking mosquito screens. A recent Australian study of short-term travelers spending $<30$ days in endemic regions in Asia during the peak rainy season reported no cases of JE [25]. In contrast, Hill and co-workers reported an incidence of 0.2 cases per million travelers [26] while an earlier study in Swiss and British travelers reported an incidence of 1.3 cases per 7.1 million travelers [27]. Even though the incidence is low, travelers from non-endemic 


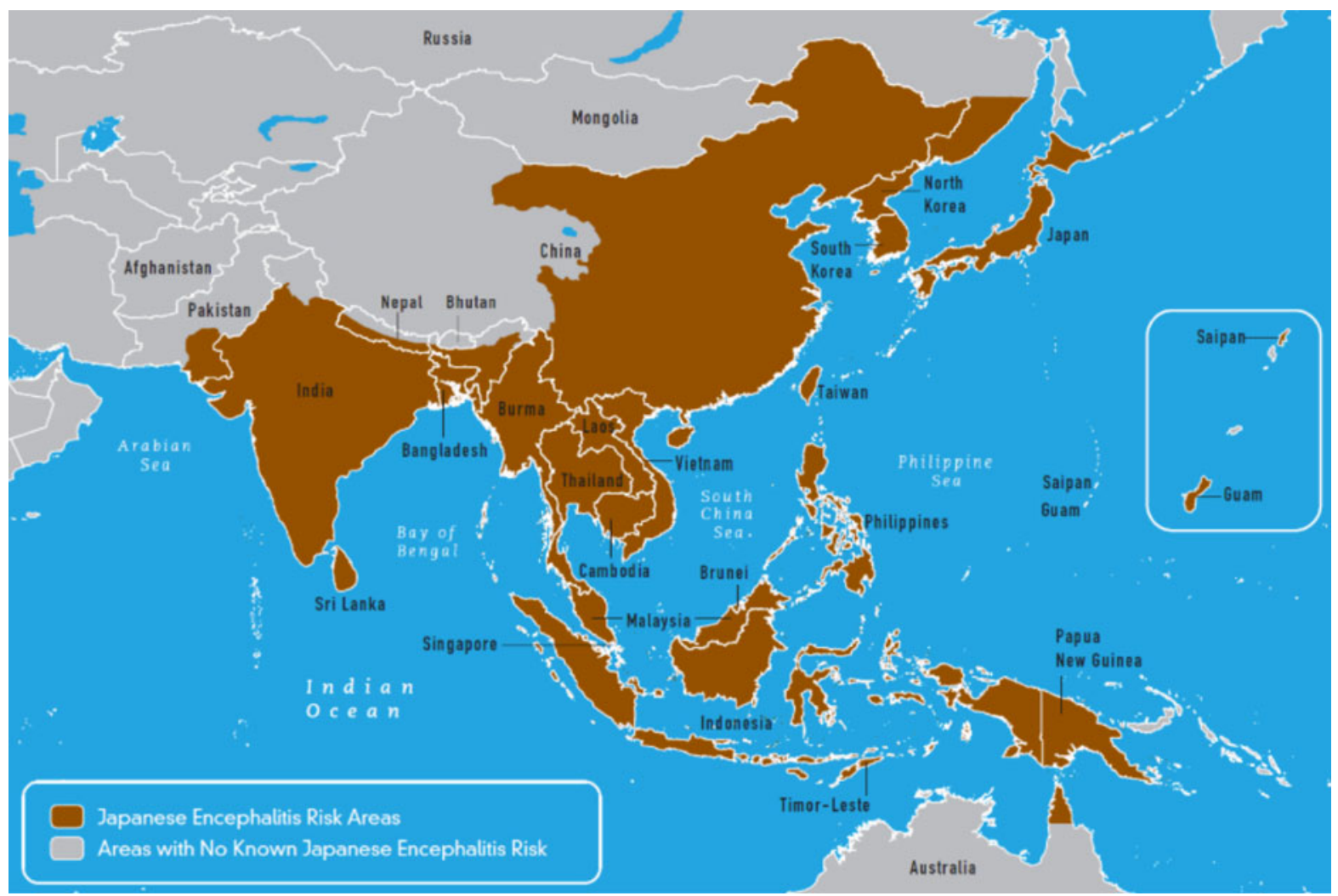

Fig. 1 Global geographical distribution of Japanese encephalitis. This figure was obtained from the United States Centers for disease control and prevention (CDC) Yellow Book [14]

countries have no pre-existing immunity and are at risk of acquiring a potentially devastating neurological infection with permanent sequelae. The need for vaccination must be weighed up against the duration of travel and the nature of activities undertaken.

\section{Clinical Manifestation of JE and Natural History}

Children aged 3-15 years old in endemic areas are highly susceptible to JE infection. The incubation period of JE infection ranges from 5 to 15 days following inoculation from an infected mosquito bite. Symptoms often begin abruptly with a non-specific febrile illness that may be self-limiting, or may progress to aseptic meningitis or encephalitis. Aseptic meningitis with nausea, vomiting headache, nuchal rigidity and photophobia is seen in $5-10 \%$ of patients, while encephalitis, the most serious manifestation of JE, is seen in up to $60-75 \%$ of patients. Encephalitis follows the febrile prodrome by $2-4$ days and is characterized by altered sensorium, motor and behavioral abnormalities. Individuals may also manifest acute flaccid paralysis with areflexia resembling poliomyelitis, seizures and movement disorders, typically choreoathetosis, myoclonus and Parkinsonism [1, 2]. In those with mild nonneurological disease, clinical improvement coincides with the onset of defervescence. However, the motor deficits, movement, behavioral, psychiatric disorders and learning deficits often persist and may take several decades to improve. These long-term sequelae 
extend the morbidity of the infection well beyond the acute period and add to the health and economic burden to local communities [28].

\section{Laboratory Diagnosis of JE Infection}

Diagnosis of acute JE infection is made by detecting JEV-specific IgM or a fourfold rise in JEV-specific IgG in the serum and cerebrospinal fluid (CSF) by capture enzyme-linked immunosorbent assay (MAC ELISA). JEVspecific IgM antibodies rise rapidly and are detectable in the CSF by day 4 after the onset of symptoms, and by day 7 in the serum, followed by a slower rise in JEV-specific IgG $[29,30]$. By day 30 after primary infection, JEVspecific IgG antibodies are detected in the serum in $100 \%$ of individuals. However, in endemic regions, JE antibodies may be confounded by cross-reacting antibodies from other flavivirus infection such as dengue, tickborn encephalitis or from previous vaccination against yellow fever or JE [31, 32]. A fourfold or greater rise in JE-specific antibodies between acute and convalescent-phase serum 2-4 weeks apart is useful in confirming acute infection and distinguishing from non-JEV flaviviral crossreacting antibodies. JEV-specific IgM may also be detectable in the CSF and has been associated with a poorer outcome [30]. JEV-specific neutralizing antibodies can also be determined by the plaque reduction neutralization test (PRNT). However, this is a labor-intensive assay and is usually only available in research and reference laboratories.

Although conventional nucleic acid amplification test of CSF and serum are not used to diagnose acute JE because viremia is short-lived and of low titer, recent advances in the real-time RT-PCR technology using loopmediated isothermal amplification (RT-LAMP) could see its use in resource-poor settings [33]. Real-time RT-LAMP is rapid test and easy to perform using a single tube assay with color detection visible to the naked eye. It has a detection limit as low as 0.1 plaque forming units (pfu). Parida et al. [34] reported a sensitivity and specificity of RT-LAMP of $100 \%$ and $86 \%$, respectively, and was able to detect serologically confirmed positive samples missed by conventional RT-PCR. Its utility and advantage over the current serological tests have not yet been determined.

\section{Treatment of JE}

There are no specific antiviral treatments for JE, and any treatments are largely supportive to control seizures, dystonia, cerebral edema and respiratory support. Clinical trials of interferon $\alpha-2 \mathrm{a}$, ribavirin and corticosteroids have failed to show improvement in clinical outcome and are not recommended [35-37]. Prevention of JE by vaccination and vector control measures remains the only enduring options to reduce the incidence of JE.

\section{JE Preventive Vaccine}

Until more recently, the prevention of JE infection has relied on the use of an inactivated mouse brain-derived vaccine developed by BIKEN in Japan since 1955 and licensed under the name of JE-VAX (BIKEN, Osaka, Japan). Although it reduced the disease burden in many JE endemic regions, it was associated with severe allergic reactions. Three vaccines have since been developed based on the neuroattenuated strain of JEV, SA14-14-2. Two of the vaccines are live-attenuated vaccines: one developed by Chengdu Institute of Biological Product, People's Republic of China, and the second, the ChimeriVax ${ }^{\mathrm{TM}}-\mathrm{JE}$ 
vaccine developed by Sanofi Pasteur. The third vaccine $\left(\right.$ IXIARO $^{\circledR} ;$ JESPECT $^{\circledR}$ in Australia) is an inactivated Vero cell-derived SA14-14-2 vaccine developed by Intercell Biomedical (Livingston, United Kingdom) and distributed by Novartis Vaccines (Surrey, United Kingdom). Table 1 [3$5,38,39]$ summarizes the key features of the inactivated IXIARO $^{\circledR}$ and live-attenuated Chengdu vaccine, while this review will focus on the ChimeriVax ${ }^{\mathrm{TM}}$-JE vaccine.

\section{ChimeriVax-JE (JE-CV)}

The ChimeriVax ${ }^{\mathrm{TM}}$-JE vaccine, also known as IMOJEV $^{\circledR}$ and JE-CV, is a live-attenuated recombinant chimeric virus vaccine based on the live-attenuated yellow fever virus (YFV) vaccine, YFV17D, in which genome sequences encoding the membrane and envelope proteins of YFV have been replaced with the corresponding genomes sequences of the attenuated JEV strain, SA-14-14-2 (Fig. 2). The ChimeriVax ${ }^{\mathrm{TM}}$-JE vaccine expresses the immunogenic envelope protein of JE, but contains the nucleocapsid protein and replication machinery of YFV17D. The ChimeriVax technology was developed by Chambers et al. [40] at St Louis University (MO, USA) and further developed into the JEchimeric virus at Acambis (Cambridge, UK) [41] before being licensed by Sanofi Pasteur.

\section{Preclinical Testing}

The ChimeriVax ${ }^{\mathrm{TM}}$-JE vaccine consists of a JEV clone derived by serial passaging of the SA1414-2 strain in serum-free Vero cell culture. The virus contains a mutation at amino acid 60 of the $\mathrm{M}$ protein that confers a capability to propagate at high viral titers without loss of the neuroattenuation phenotype [42]. Full restoration of neurovirulence to wild-type
Nakayama strain required at least four reversions in three different $\mathrm{E}$ protein domains, while two simultaneous amino acid reversions only partially restored neurovirulence [43]. Small animal model studies with intracerebral inoculation of ChimeriVax $^{\mathrm{TM}}$-JE into mice and non-human primates (rhesus and cynomolgus monkeys) have demonstrated that ChimeriVax ${ }^{\mathrm{TM}}$-JE was less neurovirulent than the parental YFV17D [44]. Extensive pre-clinical testing of ChimeriVax $^{\mathrm{TM}}$-JE also confirmed the stability of the attenuated genotype and phenotype, its robust immunogenicity, the production of lowlevel viremia in non-human primates and poor infectivity in mosquito vectors [45].

\section{Immunogenicity and Durability of the Immune Response in Adults}

One of the first human clinical trials (H-040001) examined the tolerability and immunogenicity of two doses of the ChimeriVax $^{\mathrm{TM}}$-JE vaccine compared to the live-attenuated yellow fever vaccine, YF-VAX ${ }^{\circledR}$ (Sanofi Pasteur, Lyon France), in young health adults with and without pre-existing YF immunity [46]. The ChimeriVax ${ }^{\mathrm{TM}}$-JE vaccine was well tolerated and all participants, regardless of prior YF immunity, developed neutralizing antibodies to the vaccine strain that cross-neutralized wild-type JEV.

These findings were confirmed in a subsequent study involving 99 individuals [47]. In this dose-ranging study, $100 \%$ of individuals who received a dose of $3.8 \log _{10}$ pfu developed neutralizing antibodies with a GMT of 201 (95\% CI 65-681). Cross-reactive neutralizing antibodies to the wild-type JE strains, Nakayama, Beijing- 1 and a Vietnamese 902/97 strain were detected in the sera of vaccine recipients. Previous vaccination with 


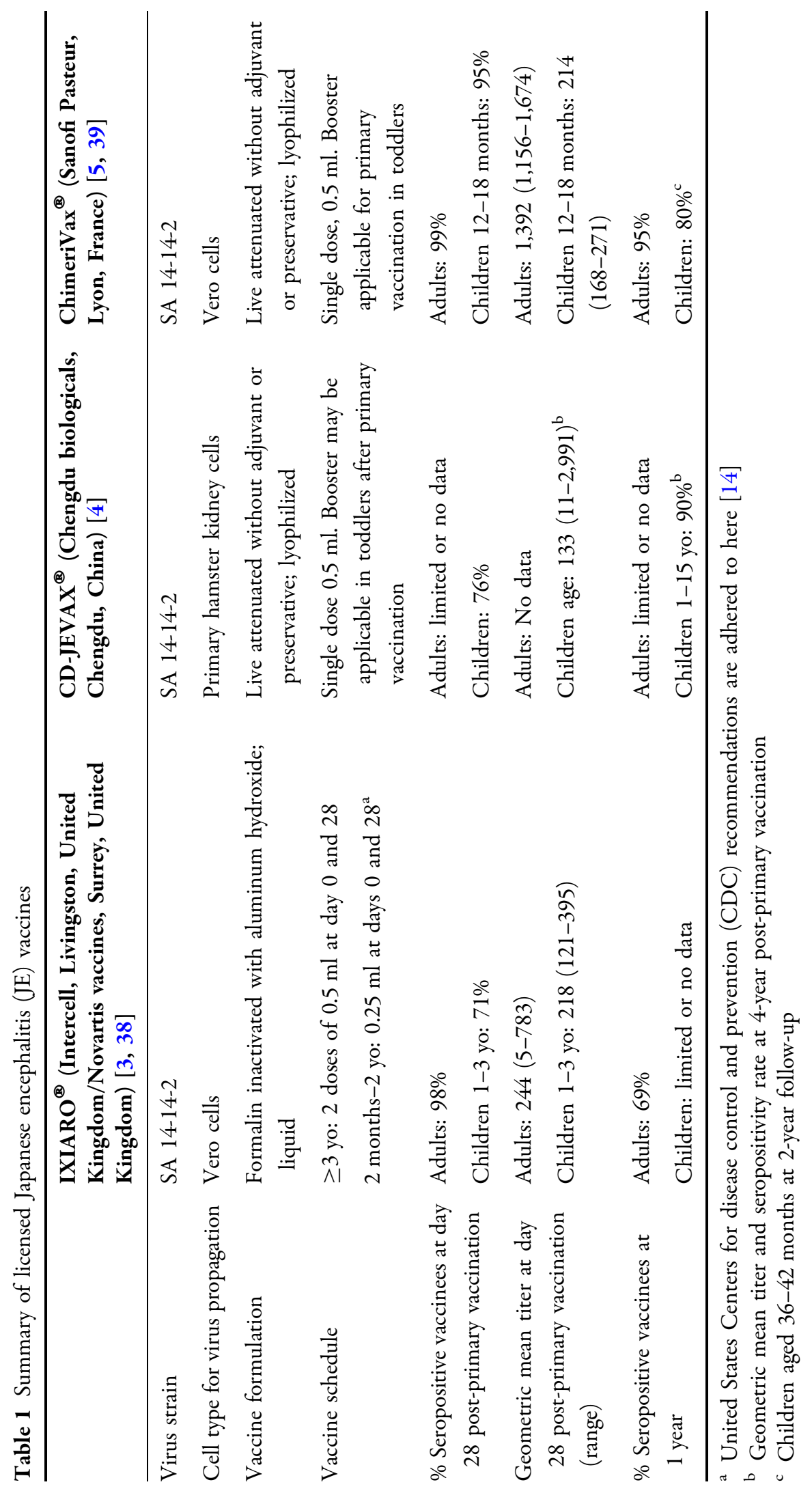


Yellow Fever Virus YF17D
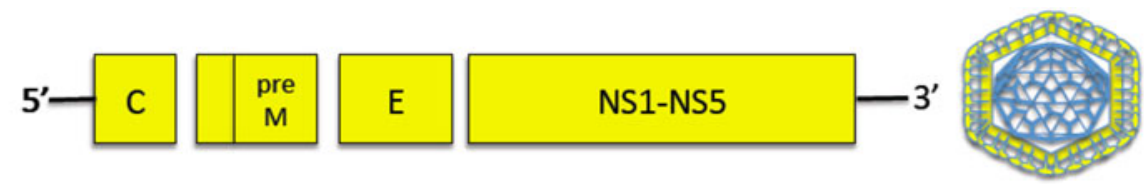

NS1-NS5

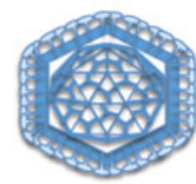

SA14-14-2
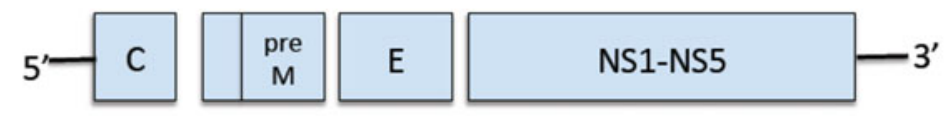

Chimeric JE Virus
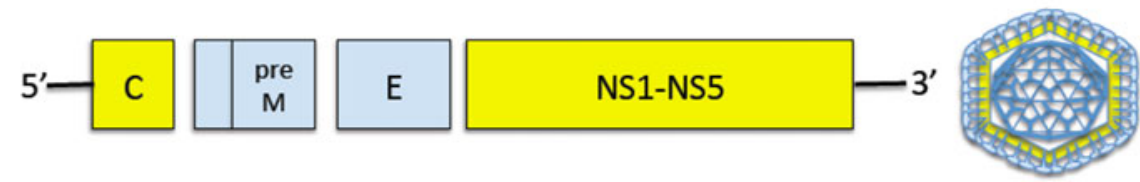

Fig. 2 Genomic organization of ChimeriVax ${ }^{\mathrm{TM}}$-JE. Genes encoding the prM and $\mathrm{E}$ proteins of the live-attenuated yellow fever virus, YF17D, are replaced by the prM and E genes of the attenuated JEV, SA14-14-2 strain. The chimeric virus replicates using the YF17D machinery but

YF-VAX ${ }^{\circledR}$ did not have a negative effect on the development of neutralizing antibody responses to ChimeriVax ${ }^{\text {TM }}$-JE.

A strong antibody response was observed after challenging a subset of ChimeriVax ${ }^{\mathrm{TM}}$-JE vaccine recipients with a single dose of inactivated mouse brain-derived JE vaccine (Nakayama strain; JE-VAX ${ }^{\circledR}$, BIKEN, Osaka, Japan) [47]. These individuals developed higher antibody titers against ChimeriVax ${ }^{\mathrm{TM}}$ JE than against wild-type strains, demonstrating that the ChimeriVax ${ }^{\mathrm{TM}}$-JE vaccine was capable of eliciting a memory immune response.

The durability and efficacy of the neutralizing antibody response to the ChimeriVax $^{\mathrm{TM}}$-JE vaccine were assessed in a 5-year follow-up study [48]. In this study, 202 young healthy participants from non-endemic countries received primary vaccination with a single dose of ChimeriVax ${ }^{\mathrm{TM}}$-JE vaccine and were then randomized to receive a booster or no booster dose at 6 months. At one month after primary vaccination, $99 \%$ of participants seroconverted and the geometric mean titer

expresses the envelope and prM proteins of JEV SA14-14-2 on its external virion. $J E$ Japanese encephalitis, $C$ core protein gene, $\operatorname{pre} M$ pre-membrane protein gene, $E$ envelope protein gene, NSI-NSS non-structural protein genes 1-5

(GMT) of neutralizing antibody obtained by PNRT that achieved a 50\% reduction on in viral plaques in Vero cell cultures ( PRNT $_{50}$ ) was 317 (95\% CI 260-385). At 6 months, 97\% (95\% CI 93-99) remained seropositive, with a GMT of 151 (95\% CI 125-181). In the group randomized to receive the booster vaccine at 6 months, $100 \%$ were seropositive 1 month after booster vaccination, with a GMT of 353, comparable to the post-primary vaccination level (95\% CI 289-432). After 5 years of followup, more than $90 \%$ of all participants remained seropositive, with $95 \% \quad(95 \%$ CI $82-99)$ seropositivity in those who received a singledose vaccine compared to $97 \%$ (95\% CI, 85-100) in those who received two doses of the vaccine. Using the Kaplan-Meier decay analysis, $87 \%$ (95\% CI 78-96) of participants who received a single vaccine and 96\% (95\% CI 89-100) of participants who received the 2-dose schedule were predicted to be still seropositive at 5-year post-vaccination [48].

This study also demonstrated that the vaccine-induced antibodies were capable of 
neutralizing wild-type JEV. Of the 197 participants, at day 28 post-vaccination, $99.5 \%$ (95\% CI 97-100) had neutralizing antibodies $\left(\mathrm{PRNT}_{50} \geq 10\right)$ to at least one strain from a panel of four wild-type JEV strains consisting of a genotype I isolate from Korea (1991 TVP-8236), a genotype II isolate from Thailand (B1034/8), a genotype III isolate from China (Beijing) and a genotype IV isolate from Indonesia (JKT 9092/TVP-6265). Up to 95\% (95\% CI 91-98) of the participants neutralized at least three of the four wild-type strains, and 85\% (95\% CI 80-90) neutralized all four wild-type strains. Of the 46 participants available at 5-year follow-up, crossneutralizing antibodies were still present in 65\% (95\% CI 50-79) of single-dose vaccinees compared to $75 \%$ (95\% CI 58-88) of those who received 2 vaccine doses.

In the pivotal Phase III trial of 820 participants, a head-to-head comparison of ChimeriVax $^{\mathrm{TM}}$-JE with the inactivated mouse brain-derived JE vaccine (Nakayama strain), JEVAX $^{\circledR}$, showed that the immunogenic response to a single dose of ChimeriVax ${ }^{\mathrm{TM}}$-JE was statistically non-inferior to the 3-dose regimen of JE-VAX ${ }^{\circledR}$ [5]. Seroconversion was recorded in $99.1 \% \quad(95 \%$ CI $98-100)$ of individuals vaccinated with ChimeriVax ${ }^{\mathrm{TM}}$-JE, compared to $95 \%$ (95\% CI 92-97) of those who received $\mathrm{JE} \mathrm{VAX}^{\circledR}$. In addition, cross-neutralizing antibodies to the Nakayama strain were present in $81 \%$ (95\% CI 76-85) of the ChimeriVax $^{\mathrm{TM}}$-JE group, compared to $75 \%$ $(95 \%$ CI 70,80$)$ in the JE-VAX ${ }^{\circledR}$ group [5].

In a follow-up study, the durability of vaccine-induced antibody was estimated by statistical modeling [49]. Based on the GMT value at 28-day post-vaccination (GMT 1392 in the ChimeriVax ${ }^{\mathrm{TM}}-\mathrm{JE}$ group), the rate of antibody decline was gradual enough to confer seroprotection for up to 10 years postvaccination. The median duration of seroprotection was estimated to exceed 20 years, suggesting that booster vaccination in adults may be unnecessary. Furthermore, repeated re-exposure to natural infection in JE endemic areas may provide sufficient natural boosting to maintain protective antibody titers $[47,48]$.

\section{The Use of ChimeriVax ${ }^{\mathrm{TM}}$-JE in Children}

Since the eradication of polio, JE is now one of the most important childhood neurological infections in infants and young children causing permanent and devastating neurological sequelae [50]. A number of trials have now been conducted in children in JE endemic regions and have reported on the safety, immunogenicity and seroprotection rates after ChimeriVax ${ }^{\mathrm{TM}}$-JE vaccination in the pediatric population.

In a phase II study of 300 Thai children aged 2-5 years who had previously received a 2-dose primary vaccination with the mouse brainderived inactivated JE vaccine, JE-VAX ${ }^{\circledR}$ (JE$\mathrm{VAX}^{\circledR}$ vaccine-primed group), vaccination with ChimeriVax $^{\mathrm{TM}}$-JE resulted in seropositivity rates of 100\% (95\% CI 96-100) [51]. This compared with $96 \%$ (95\% CI 92-98) of 200 vaccinationnaïve toddlers aged 12-24 months who received their first and only dose of ChimeriVax ${ }^{\mathrm{TM}}$-JE. The geometric mean titers, when tested against the ChimeriVax ${ }^{\mathrm{TM}}$-JE strain, were 2,634 (95\% CI 1,928-3,600) and 281 (95\% CI 219-362) in the $\mathrm{JE}-V A X^{\circledR}$ vaccine-primed and vaccine naïve groups, respectively. This suggested firstly, previous immunization with a nonChimeriVax $^{\mathrm{TM}}$-JE vaccine could elicit a robust anamnestic response to a different vaccine strain, and secondly, low antibody titers in the vaccine naïve toddlers group may be due to an immature immune system. Cross-neutralizing antibodies to wild-type JE virus were present in 
$72-81 \%$ of the $\mathrm{JE}-\mathrm{VAX}^{\circledR}$ primed group compared to $3-6 \%$ in the vaccine naïve toddlers. In the $\mathrm{JE} \mathrm{VAX}^{\circledR}$ vaccine-primed children, 99\% of children had seroprotective antibody titers against at least 3 of 4 wild-type JEV, with 89\% against 1991-TVP-8236, 89\% against B1034/8, 90\% against Beijing, and 91\% against JKT 9092/TVP-6265. In the vaccine naïve toddlers, $97 \%$ demonstrated crossneutralization against 1991-TVP-8236, 96\% against B1034/8, 97\% against Beijing, and 70\% against JKT 9092/TVP-6265. At 12 months postvaccination, the seroprotective rates remained high in both groups, $84 \%$ and $97 \%$ in the 2-5 year old children and 12-24 months old toddlers, respectively, with GMT against the ChimeriVax $^{\mathrm{TM}}$-JE strain of 454 and 62 [51].

In a subsequent Phase III study in Thailand and the Philippines involving 1,200 JE vaccine naïve children aged 12-18 months, the seroconversion rate to a single dose of ChimeriVax $^{\mathrm{TM}}$-JE was 95\% (95\% CI 93-96) with a GMT value of 214 (95\% CI 168-271) [38] against the homologous vaccine strain. In a follow-up study, the effect of booster vaccination with ChimeriVax ${ }^{\mathrm{TM}}$-JE in children aged 36-42 months who had received the primary vaccination 2 years prior was reported [52]. Of the 350 children studied, $80 \%$ of primary vaccinees had seroprotective antibodies at study commencement, albeit with low GMT values, 39 (95\% CI 34-46). Antibody titers increased by 57 -fold at 28 days after the booster vaccine with a GMT value of 2,242 (95\% CI 1,913-2,628). One year post-booster, $99 \%$ (95\% CI 98-100) of children remained seroprotected and recorded GMT values of 596 (95\% CI 502-708). In a subgroup of $14 / 345$ children who failed to seroconvert after primary vaccination, all responded to the booster vaccine and recorded GMT values of 290 (95\% CI 118-713). A further subgroup of children who were seronegative $\left(\right.$ PRNT $\left._{50}<1: 10\right) \quad 2$ years post-primary vaccination also demonstrated a robust response to a booster vaccine. The rapid anamnestic response to a booster vaccination reported here would suggest that there is value in providing a booster vaccine in toddlers who have received primary vaccination. It remains uncertain if a similar immune response to natural infection following primary vaccination in a toddler from an endemic region may be sufficient to protect from infection.

\section{Safety of ChimeriVax ${ }^{\text {TM }}$-JE and Interactions with Pre-existing Flavivirus Immunity}

There were no reported serious adverse effects related to the use of ChimeriVax ${ }^{\mathrm{TM}}$-JE vaccine in either adults or children from endemic and nonendemic countries, and in particular, no severe neurological events, allergic reactions, anaphylaxis or death. The presence of preexisting flavivirus immunity including previous vaccination with the live-attenuated YF vaccine did not cause any serious adverse events in ChimeriVax $^{\mathrm{TM}}$-JE vaccine recipients $[46,47]$.

Overall, vaccine-related reactions were observed in $52.0 \%(833 / 1,601,4,581$ events) in those who received the ChimeriVax ${ }^{\mathrm{TM}}$-JE vaccine compared to placebo, 50.6\% (204/403, 945 events) [5]. Systemic upset with fever, irritability and localized injection site reactions were the commonest adverse reactions and the reactogenicity of ChimeriVax $^{\mathrm{TM}}$-JE was similar to that of a comparator hepatitis A vaccine, Avaxim ${ }^{\circledR} 80 \mathrm{U}$ (Sanofi Pasteur, Lyon, France) [51].

Low-level viremia was detected in 5 of 300 children, all of who were asymptomatic [47]. Short-lived low-level asymptomatic viremia was also seen in some vaccinated adults with a mean peak viraemia $6.6 \mathrm{pfu} / \mathrm{ml}$, a level not expected 
to cause adverse environmental impact on transmission in mosquito vectors.

\section{CONCLUSION}

Recent years have seen considerable progress in the refinement of safe and effective vaccines against JE. There are three vaccines with good immunogenicity profile for adults and children, suitable for those in both JE-endemic and nonendemic regions, and which can be integrated into the existing childhood vaccination programs. The novel recombinant chimeric live vaccine, ChimeriVax ${ }^{\mathrm{TM}}$-JE, has been shown to be highly immunogenic in both adults and children, with a durable neutralizing antibody titers and robust anamnestic response.

\section{ACKNOWLEDGMENTS}

Prior to the peer review process, the manufacturer of the agent under review was offered an opportunity to comment on the article. Minor changes resulting from comments received were made by the author based on their scientific and editorial merit. Dr. Torresi is the guarantor for this article, and takes responsibility for the integrity of the work as a whole.

Conflict of interest. Dr. Chin declares no conflict of interest. Dr. Torresi has received an unrestricted research grant from Sanofi Pasteur.

Compliance with ethics guidelines. The analysis in this article is based on previously conducted studies, and does not involve any new studies of human or animal subjects performed by any of the authors.
Open Access. This article is distributed under the terms of the Creative Commons Attribution Noncommercial License which permits any noncommercial use, distribution, and reproduction in any medium, provided the original author(s) and the source are credited.

\section{REFERENCES}

1. Dickerson RB, Newton JR, Hansen JE. Diagnosis and immediate prognosis of Japanese B encephalitis; observations based on more than 200 patients with detailed analysis of 65 serologically confirmed cases. Am J Med. 1952;12(3):277-88.

2. Kumar R, Mathur A, Singh KB, Sitholey P, Prasad M, Shukla R, et al. Clinical sequelae of Japanese encephalitis in children. Indian J Med Res. 1993;97:9-13.

3. Tauber E, Kollaritsch $\mathrm{H}$, von Sonnenburg $\mathrm{F}$, Lademann M, Jilma B, Firbas C, et al. Randomized, double-blind, placebo-controlled phase 3 trial of the safety and tolerability of IC51, an inactivated Japanese encephalitis vaccine. J Infect Dis. 2008;198(4):493-9.

4. Sohn YM, Tandan JB, Yoksan S, Ji M, Ohrr H. A 5 -year follow-up of antibody response in children vaccinated with single dose of live attenuated SA1414-2 Japanese encephalitis vaccine: immunogenicity and anamnestic responses. Vaccine. 2008;26(13):1638-43.

5. Torresi J, McCarthy K, Feroldi E, Meric C. Immunogenicity, safety and tolerability in adults of a new single-dose, live-attenuated vaccine against Japanese encephalitis: randomised controlled phase 3 trials. Vaccine. 2010;28(50): 7993-8000.

6. Gubler D, Kuno G, Markoff L. In: Knipe D, Howley P, editors. Flaviviruses. 5th ed. Philadelphia: Lippincott William and Wilkins; 2007. p. 1155-252.

7. Pan $\mathrm{CH}$, Chen HW, Huang HW, Tao MH. Protective mechanisms induced by a Japanese encephalitis virus DNA vaccine: requirement for antibody but not CD8(+) cytotoxic T-cell responses. J Virol. 2001;75(23):11457-63.

8. Solomon T, Ni H, Beasley DW, Ekkelenkamp M, Cardosa MJ, Barrett AD. Origin and evolution of Japanese encephalitis virus in Southeast Asia. J Virol. 2003;77(5):3091-8. 
9. Li MH, Fu SH, Chen WX, Wang HY, Guo YH, Liu QY, et al. Genotype v Japanese encephalitis virus is emerging. PLoS Negl Trop Dis. 2011;5(7):e1231.

10. Endy TP, Nisalak A. Japanese encephalitis virus: ecology and epidemiology. Curr Top Microbiol Immunol. 2002;267:11-48.

11. Wu YC, Huang YS, Chien LJ, Lin TL, Yueh YY, Tseng WL, et al. The epidemiology of Japanese encephalitis on Taiwan during 1966-1997. Am J Trop Med Hyg. 1999;61(1):78-84.

12. Sohn YM. Japanese encephalitis immunization in South Korea: past, present, and future. Emerg Infect Dis. 2000;6(1):17-24.

13. Okuno T. An epidemiological review of Japanese encephalitis. World Health Stat Q. 1978;31(2): 120-33.

14. Hills SL, Weber IB, Fischer M. Japanese encephalitis: CDC health information for international travel 'Yellow Book'; 2014. http://wwwnc.cdc.gov/travel/ yellowbook/2014/chapter-3-infectious-diseasesrelated-to-travel/japanese-encephalitis. Accessed Oct 22, 2013.

15. Mani TR, Rao CV, Rajendran R, Devaputra M, Prasanna Y, Hanumaiah et al. Surveillance for Japanese encephalitis in villages near Madurai, Tamil Nadu, India. Trans R Soc Trop Med Hyg. 1991;85(2):287-91.

16. Hanna JN, Ritchie SA, Phillips DA, Lee JM, Hills SL, van den Hurk AF, et al. Japanese encephalitis in north Queensland, Australia, 1998. Med J Aust. 1999;170(11):533-6.

17. Hanna JN, Ritchie SA, Phillips DA, Shield J, Bailey MC, Mackenzie JS, et al. An outbreak of Japanese encephalitis in the Torres Strait, Australia, 1995. Med J Aust. 1996;165(5):256-60.

18. Ritchie SA, Rochester W. Wind-blown mosquitoes and introduction of Japanese encephalitis into Australia. Emerg Infect Dis. 2001;7(5):900-3.

19. Li YX, Li MH, Fu SH, Chen WX, Liu QY, Zhang HL, et al. Japanese encephalitis, Tibet, China. Emerg Infect Dis. 2011;17(5):934-6.

20. Tsai TF. New initiatives for the control of Japanese encephalitis by vaccination: minutes of a $\mathrm{WHO} /$ CVI meeting, Bangkok, Thailand, 13-15 October 1998. Vaccine. 2000;18(Suppl 2):1-25.

21. Campbell GL, Hills SL, Fischer M, Jacobson JA, Hoke $\mathrm{CH}$, Hombach JM, et al. Estimated global incidence of Japanese encephalitis: a systematic review. Bull World Health Organ. 2011;89(10): 766-74, 74A-74E.
22. Lehtinen VA, Huhtamo E, Siikamaki H, Vapalahti O. Japanese encephalitis in a Finnish traveler on a two-week holiday in Thailand. J Clin Virol. 2008;43(1):93-5.

23. Hanson JP, Taylor CT, Richards AR, Smith IL, Boutlis CS. Japanese encephalitis acquired near Port Moresby: implications for residents and travellers to Papua New Guinea. Med J Aust. 2004;181(5):282-3.

24. Caramello P, Canta F, Balbiano R, Lipani F, Ariaudo $S$, De Agostini $M$, et al. A case of imported JE acquired during short travel in Vietnam. Are current recommendations about vaccination broader? J Travel Med. 2007;14(5):346-8.

25. Ratnam I, Leder K, Black J, Biggs BA, Matchett E, Padiglione A, et al. Low risk of Japanese encephalitis in short-term Australian travelers to Asia. J Travel Med. 2013;20(3):206-8.

26. Hills SL, Griggs AC, Fischer M. Japanese encephalitis in travelers from non-endemic countries, 1973-2008. Am J Trop Med Hyg. 2010; 82(5):930-6.

27. Hatz C, Werlein J, Mutsch M, Hufnagel M, Behrens RH. Japanese encephalitis: defining risk incidence for travelers to endemic countries and vaccine prescribing from the UK and Switzerland. J Travel Med. 2009;16(3):200-3.

28. Ding D, Hong Z, Zhao SJ, Clemens JD, Zhou B, Wang B, et al. Long-term disability from acute childhood Japanese encephalitis in Shanghai, China. Am J Trop Med Hyg. 2007;77(3):528-33.

29. Solomon T, Thao LT, Dung NM, Kneen R, Hung NT, Nisalak A, et al. Rapid diagnosis of Japanese encephalitis by using an immunoglobulin $\mathrm{M}$ dot enzyme immunoassay. J Clin Microbiol. 1998; 36(7):2030-4.

30. Burke DS, Nisalak A, Ussery MA, Laorakpongse T, Chantavibul S. Kinetics of IgM and IgG responses to Japanese encephalitis virus in human serum and cerebrospinal fluid. J Infect Dis. 1985;151(6): 1093-9.

31. Martin DA, Biggerstaff BJ, Allen B, Johnson AJ, Lanciotti RS, Roehrig JT. Use of immunoglobulin $\mathrm{m}$ cross-reactions in differential diagnosis of human flaviviral encephalitis infections in the United States. Clin Diagn Lab Immunol. 2002;9(3):544-9.

32. Innis BL, Nisalak A, Nimmannitya S, Kusalerdchariya S, Chongswasdi V, Suntayakorn S, et al. An enzyme-linked immunosorbent assay to characterize dengue infections where dengue and Japanese encephalitis co-circulate. Am J Trop Med Hyg. 1989;40(4):418-27. 
33. Toriniwa H, Komiya T. Rapid detection and quantification of Japanese encephalitis virus by real-time reverse transcription loop-mediated isothermal amplification. Microbiol Immunol. 2006;50(5):379-87.

34. Parida MM, Santhosh SR, Dash PK, Tripathi NK, Saxena P, Ambuj S, et al. Development and evaluation of reverse transcription-loop-mediated isothermal amplification assay for rapid and realtime detection of Japanese encephalitis virus. J Clin Microbiol. 2006;44(11):4172-8.

35. Kumar R, Tripathi P, Baranwal M, Singh S, Tripathi S, Banerjee G. Randomized, controlled trial of oral ribavirin for Japanese encephalitis in children in Uttar Pradesh. India. Clin Infect Dis. 2009; 48(4):400-6.

36. Hoke CH Jr, Vaughn DW, Nisalak A, Intralawan P, Poolsuppasit S, Jongsawas V, et al. Effect of highdose dexamethasone on the outcome of acute encephalitis due to Japanese encephalitis virus. J Infect Dis. 1992;165(4):631-7.

37. Solomon T, Dung NM, Wills B, Kneen R, Gainsborough M, Diet TV, et al. Interferon alfa-2a in Japanese encephalitis: a randomised doubleblind placebo-controlled trial. Lancet. 2003;361 (9360):821-6.

38. Feroldi E, Pancharoen C, Kosalaraksa P, Watanaveeradej V, Phirangkul K, Capeding MR, et al. Single-dose, live-attenuated Japanese encephalitis vaccine in children aged 12-18 months: randomized, controlled phase 3 immunogenicity and safety trial. Hum Vaccin Immunother. 2012;8(7):929-37.

39. Kaltenbock A, Dubischar-Kastner K, Schuller E, Datla M, Klade CS, Kishore TS. Immunogenicity and safety of IXIARO (IC51) in a Phase II study in healthy Indian children between 1 and 3 years of age. Vaccine. 2010;28(3):834-9.

40. Chambers TJ, Nestorowicz A, Mason PW, Rice CM. Yellow fever/Japanese encephalitis chimeric viruses: construction and biological properties. J Virol. 1999;73(4):3095-101.

41. Guirakhoo F, Zhang ZX, Chambers TJ, Delagrave S, Arroyo J, Barrett AD, et al. Immunogenicity, genetic stability, and protective efficacy of a recombinant, chimeric yellow fever-Japanese encephalitis virus (ChimeriVax-JE) as a live, attenuated vaccine candidate against Japanese encephalitis. Virology. 1999;257(2):363-72.

42. Guy B, Guirakhoo F, Barban V, Higgs S, Monath TP, Lang J. Preclinical and clinical development of YFV
17D-based chimeric vaccines against dengue, West Nile and Japanese encephalitis viruses. Vaccine. 2010;28(3):632-49.

43. Arroyo J, Guirakhoo F, Fenner S, Zhang ZX, Monath TP, Chambers TJ. Molecular basis for attenuation of neurovirulence of a yellow fever virus/Japanese encephalitis virus chimera vaccine (ChimeriVax-JE). J Virol. 2001;75(2): 934-42.

44. Levenbook IS, Pelleu LJ, Elisberg BL. The monkey safety test for neurovirulence of yellow fever vaccines: the utility of quantitative clinical evaluation and histological examination. J Biol Stand. 1987;15(4):305-13.

45. Hardy F. In: Monath TP, editor. Susceptibility and resistance of vector mosquitoes. Boca Raton: CRC Press; 1988.

46. Monath TP, McCarthy K, Bedford P, Johnson CT, Nichols R, Yoksan S, et al. Clinical proof of principle for ChimeriVax: recombinant live, attenuated vaccines against flavivirus infections. Vaccine. 2002;20(7-8):1004-18.

47. Monath TP, Guirakhoo F, Nichols R, Yoksan S, Schrader R, Murphy C, et al. Chimeric live, attenuated vaccine against Japanese encephalitis (ChimeriVax-JE): phase 2 clinical trials for safety and immunogenicity, effect of vaccine dose and schedule, and memory response to challenge with inactivated Japanese encephalitis antigen. J Infect Dis. $2003 ; 188(8): 1213-30$.

48. Nasveld PE, Ebringer A, Elmes N, Bennett S, Yoksan $\mathrm{S}$, Aaskov J, et al. Long term immunity to live attenuated Japanese encephalitis chimeric virus vaccine: randomized, double-blind, 5-year phase II study in healthy adults. Hum Vaccin. 2010;6(12):1038-46.

49. Desai K, Coudeville L, Bailleux F. Modelling the long-term persistence of neutralizing antibody in adults after one dose of live attenuated Japanese encephalitis chimeric virus vaccine. Vaccine. 2012;30(15):2510-5.

50. Halstead SB, Jocobson J. Japanese encephalitis virus vaccines. In: Plotkin S, Orenstien W, Offit P, editors. Vaccines. 5th ed. New York: Saunders Elsevier; 2008. p. 311-52.

51. Chokephaibulkit K, Sirivichayakul C, Thisyakorn U, Sabchareon A, Pancharoen C, Bouckenooghe A, et al. Safety and immunogenicity of a single administration of live-attenuated Japanese encephalitis vaccine in previously primed 2- to 5 -year-olds and naive 12 - to 24-month-olds: 
multicenter randomized controlled trial. Pediatr Infect Dis J. 2010;29(12):1111-7.

52. Feroldi E, Capeding MR, Boaz M, Gailhardou S, Meric C, Bouckenooghe A. Memory immune response and safety of a booster dose of Japanese encephalitis chimeric virus vaccine (JE-CV) in JE$\mathrm{CV}$-primed children. Hum Vaccin Immunother. 2013;9(4):889-97. 